\title{
Variação diacrônica e ensino
}

\section{The diachronic variation and the teaching}

\author{
Fabrício da Silva Amorim ${ }^{1}$
}

\begin{abstract}
Resumo: O objetivo deste trabalho é refletir sobre a (in)visibilidade da variação diacrônica no ensino de língua portuguesa a partir das seguintes questões: i) por que a mudança linguística deve figurar no rol de conteúdos da disciplina Língua Portuguesa?; ii) que subsídios são fornecidos pelos livros didáticos do Ensino Médio para a abordagem da variação diacrônica? e iii) como o professor pode trabalhar com esse tipo de variação? Para tanto, analisam-se livros didáticos de quatro coleções recomendas pelo PNLD (2018) "Linguagem e Interação" (FARACO; MOURA; MORUXO Jr., 2016); "Português Contemporâneo: diálogo, reflexão e uso" (CEREJA;VIANNA; DAMIEN, 2016); "Esferas da Linguagem" (CAMPOS; ASSUMPÇÃO, 2016) e "Novas Palavras" (AMARAL et al., 2016) - e apresentam-se sugestões didáticas que, a partir da articulação de conteúdos de Literatura e de Análise Linguística, viabilizam um trabalho com a variação diacrônica alinhado ao eixo "uso-reflexão-uso" proposto pelos PCN (1998).
\end{abstract}

Palavras-chave: Variação diacrônica; Ensino; Livro didático.

Abstract: The purpose of this paper is to reflect on the (in)visibility of diachronic variation in the teaching of Portuguese language. To do so, it considers the questions as follow: i) why must linguistic change be a topic in the teaching of Portuguese? ii) Which tools are provided by Portuguese textbooks for approaching the diachronic variation? And iii) How should Portuguese teachers work with this type of linguistic variation? Four collections of textbooks - recommended by the Brazilian Program for textbook - are analyzed: "Linguagem e Interação" (FARACO; MOURA; MORUXO Jr., 2016); Português Contemporâneo: diálogo, reflexão e uso" (CEREJA;VIANNA; DAMIEN, 2016); "Esferas da Linguagem" (CAMPOS; ASSUMPÇÃO, 2016) and "Novas Palavras" (AMARAL et al., 2016). This paper also presents pedagogic suggestions for approaching historical variation under an interdisciplinary perspective, which, in turn, is aligned with Brazilian National Curriculum Parameters (1998).

Keywords: Diachronic variation; Teaching; Textbooks.

\section{Apresentação}

No Brasil, sob diferentes perspectivas da Linguística, têm sido empreendidas pesquisas com preocupações pedagógicas, que visam a oferecer contributos para tornar o ensino de português mais democrático e eficiente.

\footnotetext{
1 Professor de Língua Portuguesa do Instituto Federal da Bahia - IFBA/Valença. Doutor em Estudos Linguísticos (UNESP). E-mail:
} fabricioamorim6@gmail.com 
Destacam-se, entre essas pesquisas, trabalhos que, assentados na Sociolinguística Variacionista e no (Sócio)Funcionalismo, buscam instrumentalizar professoras e professores de Português para a abordagem de fenômenos variáveis da língua (AMORIM, 2014; MARTINS; VIERA; TAVARES, 2014; MARTINS; TAVARES, 2013; DUARTE, 2013; GÖRSKI; COELHO, 2009).

No entanto, constata-se que, muitas vezes, o tratamento dado à variação é, além de estereotipado, não funcional, na medida em que os materiais didáticos, em sua maioria, apenas descrevem casos de variação diatópica nos níveis fonético-fonológico e, principalmente, lexical (ARAÚJO; PEREIRA, 2017; LIMA, 2014; DUARTE, 2013).

Pouco ou nenhum espaço é dado a fenômenos de mudança linguística, representativos da chamada variação diacrônica ou histórica. Entre as razões aventadas para explicar a escassez da abordagem da mudança linguística em materiais didáticos e, por conseguinte, no ensino de Português, pode-se destacar que, tanto nos Parâmetros Curriculares Nacionais (PCN) de Língua Portuguesa, quanto no Guia do Programa Nacional do Livro Didático (PNLD), não há referências claras à variação diacrônica. $A$ proposta recente da Base Nacional Comum Curricular (BNCC), embora apresente, em relação aos PCN, avanços quanto ao detalhamento de conteúdos da disciplina Língua Portuguesa, também negligencia a mudança linguística como tópico de ensino.

Dessa forma, nota-se que a variação diacrônica, imprescindível à compreensão de fenômenos que atestam a heterogeneidade linguística, tem presença restrita ou totalmente nula nas aulas de Português. É preciso, portanto, que a relevância desse tipo de variação para o ensino seja reconhecida, visto que a abordagem adequada da mudança linguística garante a compreensão de fenômenos recentes de variação sincrônica, o que, por sua vez, contribui para o combate ao preconceito linguístico.

Este artigo pretende, então, discutir a (in)visibilidade da variação diacrônica no ensino de língua portuguesa, partindo das seguintes questões motivadoras:

i) Por que a mudança linguística deve figurar no rol de conteúdos da disciplina Língua Portuguesa?

ii) Que subsídios são fornecidos pelos livros didáticos do Ensino Médio para a abordagem da variação diacrônica?

iii) Como o professor pode trabalhar com esse tipo de variação?

Desse modo, para responder a essas questões, o presente trabalho pauta-se pela Pedagogia da Variação Linguística, também de chamada de Sociolinguística Educacional, para promover reflexões acerca da abordagem da mudança linguística no ensino de Português. Além disso, parte da análise de quatro coleções de livros didáticos destinados ao Ensino Médio e aprovadas no PNLD (2018), a fim de discutir o lugar da variação diacrônica em materiais didáticos e, por conseguinte, nas aulas de Português.

O texto está organizado em cinco seções. Após esta introdução, a seção 2 apresenta um conjunto de trabalhos recentes representativos da Pedagogia da Variação Linguística. Na seção 3, descrevem-se o material de análise e os procedimentos metodológicos. A seção 4 discute os resultados da análise dos livros didáticos, e a seção 5 elenca sugestões didáticas para a abordagem da variação diacrônica. As considerações finais constam da última seção. 


\section{Ensino sociolinguístico de Português}

Os aspectos teóricos e pedagógicos cotejados ao longo deste trabalho são fornecidos pela Pedagogia da Variação Linguística (MARTINS; VIEIRA; TAVERES, 2014; ZILLES; FARACO, 2015; MARTINS; TAVARES, 2013; GÖRSKI; COELHO, 2009), vertente da linguística moderna que representa uma proposta de aplicação pedagógica da Sociolinguística Variacionista.

Desde os anos 1980, as teorias linguísticas têm dialogado com o ensino de Português, propondo reformulações em seus objetivos e metodologias. No entanto, esse diálogo ainda se mostra tímido, visto que ainda impera, nas escolas brasileiras, a falácia de que o trabalho baseado, exclusivamente, na gramática normativa representa o método mais eficaz de ensino da língua materna (MARINE; BARBOSA, 2016).

Marine e Barbosa (2016), ao refletirem sobre a discrepância existente entre as recomendações dos PCN (1998) e o ensino de Português predominante no Brasil, apontam três fatores que têm dificultado a adoção da Pedagogia da Variação Linguística: 1) a crença equivocada de que a língua é representada apenas pela norma-padrão, devendo a escola ensiná-la, por meio de aulas de gramática, a fim de que o aluno aprenda a falar e a escrever "certo"2; 2) a resistência que muitas professoras e professores de Português encontram, por parte da escola e dos pais de alunos, que esperam um ensino tradicional, gramatiqueiro e 3) a dificuldade que essas/esses profissionais têm de transpor a teoria para a prática, já que, em geral, não contam com o auxílio de uma material didático elaborado a partir dessa perspectiva de interface entre a Linguística e o ensino.

Assim, a Sociolinguística, em sua vertente educacional, tem fornecido subsídios teóricopedagógicos para uma ruptura no ensino tradicional de Português: a natureza variável e mutável da língua requer uma metodologia que a aborde em sua heterogeneidade. Espera-se, com isso, consolidar, na escola, o reconhecimento de que todas as variedades linguísticas são legítimas, na medida em que representam modos alternativos de dizer a mesma coisa, devendo ser pedagogicamente exploradas para o desenvolvimento de habilidades linguísticas.

Nessa perspectiva, as aulas de Português, alinhando-se às diretrizes dos PCN e, mais recentemente, da BNCC3, devem: i) valorizar os mais diversos falares, contribuindo para fortalecer a autoestima (linguística) do aluno que, geralmente, chega à escola sem o domínio da norma culta; ii) combater o preconceito linguístico, evidenciando as razões ideológicas e socioculturais responsáveis por estigmatizar certos usos linguísticos; e iii) proporcionar o contato do aluno com as normas cultas e a

\footnotetext{
2 Uma explicação possível para a lenta superação dos moldes tradicionais de ensino da Língua Portuguesa é apresentada em Amorim (2014). Segundo o autor, a sociedade brasileira e suas instituições, como a escola, estão sob a influência constante da colonialidade, considerada uma consequência ideológica do processo de colonização a que o Brasil foi submetido. Nessa perspectiva, a persistência do ensino de português baseado na gramática normativa explicita a subserviência à norma-padrão. Ou seja, focar uma variedade lusitanizante no ensino de Português significa um ato de "civilidade linguística", na medida em que se apresenta aos estudantes a forma mais "correta" - europeia - para se comunicar.

${ }^{3}$ A BNCC - Base Nacional Comum Curricular - tem configurado como um documento oficial de grande relevância para qualquer discussão de caráter pedagógico no Brasil. Em relação ao ensino de Língua Portuguesa, no Ensino Fundamental (a versão dedicada ao Ensino Médio, por ora, encontra-se em elaboração), a BNCC preserva as diretrizes dos PCN, defendendo uma abordagem (socio)linguística da língua e a didatização dos gêneros textuais. Embora haja questionamentos sobre a sua natureza política, esse documento apresenta avanços em relação aos PCN, pois coloca muitas de suas diretrizes em termos mais práticos, especificando, por exemplo, um conjunto de gêneros textuais que podem ser utilizados para um trabalho com o eixo da oralidade em sala de aula.
} 
norma-padrão4, para que ele possa utilizá-las nas demandas sociais que exigirem o seu uso. Em outras palavras:

\begin{abstract}
[...] a escola não pode ignorar as diferenças sociolinguísticas. Professores e alunos devem estar conscientes de que existem duas ou mais maneiras de dizer a mesma coisa. A escola deve incentivar o emprego criativo e competente do Português, contribuindo, assim, para o desenvolvimento de um sentimento de segurança em relação ao uso da língua. Essa postura respeitosa no trato das diferenças socioculturais e linguísticas é um compromisso dos professores. (COAN; FREITAG, 2010, p. 180).
\end{abstract}

Assim, a defesa de um ensino sociolinguístico de Português encontra respaldo nos PCN (1998): como assinalam Coan e Freitag (2010), é possível depreender desse documento vários princípios de base sociolinguística, evidenciados, por exemplo, nas muitas diretrizes que recomendam a abordagem da variação linguística nas atividades didáticas de Português, objetivando aumentar o grau de letramento dos alunos, ampliar seu repertório linguístico e auxiliá-los nos "usos públicos da linguagem", isto é, nos usos linguísticos destinados às demandas sociais.

Desse modo, avanços devem ser reconhecidos em relação à implementação da Pedagogia da Variação Linguística nas escolas brasileiras. Parte deles advém de mudanças observadas nos livros didáticos de Português, que, avaliados e distribuídos pelo PNLD, fornecem a professoras e professores caminhos para uma abordagem sociolinguística na sala de aula. Além da proposição de conteúdos e atividades que levam os alunos a reconhecerem a heterogeneidade linguística, muitos desses livros contêm manuais que auxiliam essas/esses profissionais a adquirirem/resgatarem uma formação sociolinguística.

No entanto, conforme alerta Lima (2014, p. 119), o fato de abordar a variação não deve ser visto como um mérito dos livros didáticos mais recentes, uma vez que "se pode considerar que a inserção do tema não obedece a um critério científico ou social, mas sim a um critério formal de avaliação": a abordagem da variação é uma das principais exigências para a aprovação de um livro didático pelo PNLD.

Nesse sentido, verifica-se que, em muitos livros didáticos, o tratamento dado à variação é, além de estereotipado, não funcional, já que apenas descrevem casos de variação diatópica nos níveis fonéticofonológico e, principalmente, lexical, (ARAÚJO, PEREIRA, 2017; LIMA, 2014; DUARTE, 2013), conforme explica, enfaticamente, Duarte (2013):

\begin{abstract}
Sim, nossos livros limitam o tratamento da variação aos "sotaques regionais" e às diferenças lexicais que caracterizam essa ou aquela região! As diferenças morfossintáticas entre o português nosso de cada dia e a escrita não são sequer mencionadas pela maioria dos livros. (DUARTE, 2013, p. 47)
\end{abstract}

Em relação a fenômenos de mudança linguística, representativos da chamada variação diacrônica ou histórica, pouquíssimo ou nenhum espaço é dado nos materiais didáticos de Português. Como se

\footnotetext{
${ }^{4}$ Neste trabalho, o termo norma culta refere-se às variedades do português utilizadas por falantes com níveis elevados de letramento, em situações mais monitoradas. Trata-se, portanto, de usos reais que constituem a norma de prestígio do português. Por sua vez, normapadrão diz respeito à variedade prescrita pelas gramáticas normativas mais tradicionais e em uso apenas nos gêneros textuais escritos altamente monitorados. Representa, assim, uma norma abstrata (Cf. AMORIM, 2014).
} 
discute adiante, o reconhecimento da natureza mutável da língua, embora presente nos livros didáticos de edições recentes, é feito, geralmente, sob uma perspectiva meramente classificatória, em (sub)seções dedicadas a apresentar os tipos de variação/variedades linguísticas.

A conclusão é a de que a variação diacrônica é notadamente negligenciada no ensino de Português, o que se deve, entre outros fatores, à carência de referências claras à sua abordagem tanto no guia do PNLD quanto nos documentos de diretrizes para o ensino (PCN e BNCC). Mesmo na pesquisa linguística sob o viés pedagógico, há uma enorme escassez de trabalhos sobre o tratamento da variação diacrônica na sala de aula.

Dessa forma, torna-se evidente a necessidade de refletir sobre o papel da variação diacrônica/histórica no ensino de Português, a fim de, reconhecidas as suas contribuições para a formação (socio)linguística dos estudantes, resgatá-la da condição de um conteúdo negligenciado. Nesse sentido, o presente trabalho se propõe a incitar essa reflexão, apontando caminhos para um ensino funcional da análise linguística, na Educação Básica, também sob o viés diacrônico. Na seção seguinte, apresentam-se as decisões metodológicas assumidas para a condução desta pesquisa, além da descrição do material analisado.

\section{Decisões metodológicas}

O ponto de partida da reflexão aqui proposta é análise de livros didáticos de quatro coleções do Ensino Médio, aprovadas pelo PNLD (2018): "Linguagem e Interação" (FARACO; MOURA; MORUXO Jr., 2016); "Português Contemporâneo: diálogo, reflexão e uso" (CEREJA;VIANNA; DAMIEN, 2016); "Esferas da Linguagem" (CAMPOS; ASSUMPÇÃO, 2016) e "Novas Palavras" (AMARAL et al., 2016).

O livro didático, ainda que não seja distribuído em todas as escolas do país, constitui o material didático a que a grande maioria de professoras e professores recorre para a elaboração de suas aulas. Dessa forma, embora se defenda a autonomia da/do professora/professor para questionar e elaborar seus materiais didáticos, pode-se afirmar que, na realidade brasileira, em que, por razões amplamente conhecidas, as/os profissionais da Educação dispõem de pouco tempo e condições para a formação contínua, o livro didático acaba assumindo um papel notável nas suas decisões pedagógicas. Conduzir uma reflexão a partir da análise desse material, portanto, licencia generalizações capazes de promover a compreensão de muitas questões relativas ao ensino no País.

Conforme assinalado, a grande maioria dos trabalhos assentados na perspectiva da Pedagogia da Variação Linguística não foca a variação diacrônica, incluindo-se os que executam análise de livros didáticos. A ausência da abordagem desse tipo de variação, como também apontado, estende-se aos documentos pedagógicos oficiais, sejam normatizadores, sejam consultivos. Por conseguinte, não se deve esperar que as coleções de livros didáticos, mesmo as mais recentes, abordem a variação diacrônica, ostensivamente, em seus diferentes volumes. Com base nessa inferência, selecionou-se, para análise, apenas um volume de cada coleção, qual seja, o volume destinado a $1^{\text {a }}$ série do Ensino Médio, quando a variação linguística figura, mais explicitamente, como um "conteúdo" obrigatório. 
Assim, em cada exemplar, foi analisada a (sub)seção destinada à variação e, como na $1^{a}$ série do Ensino Médio também são apresentados os primórdios da história da Literatura de Língua Portuguesa ${ }^{5}$, considerou-se, ainda, a seção relativa ao estudo do Trovadorismo ${ }^{6}$. Delimitado o escopo de análise, buscou-se identificar se o livro apresentava: i) (sub)seção exclusivamente destinada à variação diacrônica; ii) atividades de análise linguística em perspectiva diacrônica; iii) abordagem interdisciplinar considerando os eixos Língua e Literatura - para o tratamento da variação histórica; e iv) propostas de projeto com foco em fenômenos de mudança linguística. Na seção a seguir, discutem-se os resultados da análise.

\section{A variação diacrônica no livro didático de Português}

A análise dos livros didáticos selecionados, conforme aventado, revela que a variação diacrônica é negligenciada como conteúdo de Língua Portuguesa. De modo geral, a abordagem desse tipo de variação é meramente classificatória, carecendo de articulações com tópicos de Análise Linguística e de Literatura. O quadro abaixo exibe o resultado geral da análise:

Quadro 1: Abordagem da variação diacrônica em livros didáticos de Português

\begin{tabular}{|c|c|c|c|c|}
\hline Livro didático (1 1 a série do EM) & $\begin{array}{c}\text { Seção destinada } \\
\text { à variação } \\
\text { diacrônica }\end{array}$ & $\begin{array}{c}\text { Abordagem } \\
\text { interdisciplinar } \\
\text { da variação } \\
\text { diacrônica }\end{array}$ & $\begin{array}{c}\text { Análise linguística } \\
\text { em perspectiva } \\
\text { diacrônica }\end{array}$ & $\begin{array}{c}\text { Proposta de } \\
\text { projeto baseado } \\
\text { na variação } \\
\text { diacrônica }\end{array}$ \\
\hline $\begin{array}{c}\text { Língua portuguesa: linguagem } \\
\text { interação (FARACO; MOURA; } \\
\text { MARUXO Jr., 2016) }\end{array}$ & Não & Não & Não & Não \\
\hline $\begin{array}{c}\text { Português contemporâneo: } \\
\text { diálogo, reflexão e uso (CEREJA; } \\
\text { VIANNA; DAMIEN, 2016) }\end{array}$ & $\operatorname{Sim}$ & Não & Sim & Não \\
\hline $\begin{array}{c}\text { Esferas das linguagens } \\
\text { (CAMPOS; ASSUMPÇÃO, 2016) }\end{array}$ & $\operatorname{Sim}$ & Não & Não & Não \\
\hline $\begin{array}{c}\text { Novas palavras (AMARAL et al., } \\
\text { 2016) }\end{array}$ & $\operatorname{Sim}$ & Não & & \\
\hline
\end{tabular}

Como se observa, a presença da variação diacrônica no material analisado é bastante restrita e, no caso da coleção "Língua portuguesa: linguagem e interação" (FARACO; MOURA; MARUXO Jr., 2016), nula. Vale salientar, contudo, que não se deseja, no presente trabalho, questionar a qualidade dessa e das

\footnotetext{
${ }^{5}$ Vale lembrar que muitos livros didáticos atuais não tratam da produção literária medieval, passando a abordar a história da Literatura a partir das suas primeiras manifestações na Idade Moderna. É o que se observa em Amaral et al (2016). Outro fato interessante é que, em algumas coleções, como a de Campos e Assumpção (2016), a abordagem da história da Literatura inicia-se no volume destinado a $2^{a}$ série do Ensino Médio.

${ }^{6} \mathrm{O}$ recorte adotado se restringiu aos primórdios da Literatura de Língua Portuguesa, cuja produção é tradicionalmente rotulada como trovadoresca. Não se analisou, portanto, o capítulo que trata da gênese da Literatura no Brasil, embora também pudesse fornecer elementos para uma abordagem interdisciplinar da variação histórica da língua.
} 
demais coleç̃oes consultadas: o fato de terem sido aprovadas no PNLD (2018) atribui-Ihes o caráter de um recurso adequado para intermediar o ensino-aprendizagem de Língua Portuguesa no Ensino Médio.

A coleção de Faraco, Moura e Maruxo Jr. (2016), por exemplo, representa um material bastante alinhado à proposta de ensino de leitura e produção textual baseado nos gêneros textuais, uma vez que a construção de cada capítulo é norteada por um gênero a partir do qual se articulam conteúdos da tríade Língua(gem)/Literatura/Produção de Texto. Quanto ao tratamento da variação, nota-se que os autores, no volume analisado, focam aspectos diafásicos, isto é, relacionados aos usos variáveis da língua em diferentes situações de comunicação - faladas e escritas.

Transcreve-se abaixo a seção em que Faraco, Moura e Maruxo Jr. (2016), mais diretamente, referem-se à variação linguística. Como se vê, enfatizam apenas a variação estilística:

\begin{abstract}
As variedades linguísticas e os níveis de linguagem.
Os falantes de uma língua nem sempre se expressam do mesmo modo. As diferenças ocorrem pelos mais diversos fatores: a região de origem do falante, a faixa etária, o grau de escolaridade, a classe ou grupo social a que ele pertence, entre muitos outros. Essas diferenças determinam as variedades linguísticas.

Além disso, há situações em que se pode utilizar a língua de maneira mais descontraída, menos formal (por exemplo, em casa, numa conversa entre amigos, numa carta pessoal, num diário íntimo), e outras em que é preciso um grau maior de formalidade (em situações de comunicação solene, no trabalho, nas comunicações orais ou escritas públicas - jornal, rádio, etc.). Formalidade e informalidade são níveis de linguagem.

As variedades formais de maior prestígio social, utilizadas nas comunicações formais públicas, são chamadas, em seu conjunto, de normas urbanas de prestígio.

Nas aulas de Língua Portuguesa, uma das coisas que você aprende é utilizar convenientemente as variedades linguísticas e os níveis de linguagem, adaptando-os às diferentes situações e finalidades comunicativas do seu dia a dia. (FARACO; MOURA; MARUXO Jr., 2016, p. 39).
\end{abstract}

Em Cereja, Vianna e Damien (2016), o reconhecimento da variação diacrônica aparece já nas primeiras páginas do capítulo dedicado à variação linguística. Por meio de uma atividade baseada na canção "Vozes da seca", de Luís Gonzaga e Zé Dantas, os autores exploram aspectos ortográficos e morfossintáticos do texto sob o viés da variação (diastrática e diacrônica).

Desse modo, uma das questões da atividade, que se refere às formas "vosmicê" e "mercê", presentes na canção, exibe um continuum de mudança - vossa mercê > vosmicê > você -, recurso bastante ilustrativo para tratar da variação diacrônica. Nesse sentido, essa atividade caracteriza-se como uma proposta de análise linguística em perspectiva diacrônica. Após a atividade, a variação diacrônica tem espaço na subseção que apresenta os tipos de variação:

\footnotetext{
Variação diacrônica

Releia dois trechos das cantigas reproduzidas neste capítulo, na seção Literatura:

Passa seu amigo, /que Ihi ben queria;/o cervo do monte/a augua volvia, /leda dos amores, /dos amores leda. (Pero Meogo)

Quantos an gran coita d'amor/eno mundo, qual og'eu sei, /querrian morrer, eu o sei,/o averrian én sabor./Mais mentr'eu vos vir,' mia senhor,/sempre m'eu querria viver,/e atender e atender! (João Garcia de Guilhade)

Nesses trechos, conseguimos reconhecer algumas palavras que utilizamos hoje em dia, como "Ihi", "ben", "augua", "gran", "og", "ei", "querrian", "averrian" e "mia", que correspondem, respectivamente, a Ihe, bem, água, grande, hoje, hei, queriam, haveriam e minha.
} 
Essa variação na língua, que ocorre através do tempo, é chamada de diacrônica. É possível, assim, considerar que o português arcaico, ou galego-português, é uma variedade antiga do português atual.

Não é preciso voltar séculos no tempo para perceber esse tipo de variação. Na canção "Vozes da seca" há os termos vosmicê e mercê, equivalentes, hoje, a você, ocê, cê. Diferenças no uso da língua entre gerações que convivem em uma mesma época também constituem a variação diacrônica, da qual são exemplos expressões e gírias usadas apenas por nossos pais ou avós.

(CEREJA; VIANNA; DAMIEN, 2016, p. 51).

Destaca-se também que, para encerrar o capítulo sobre variação, os autores propõem uma atividade que, novamente, incide no reconhecimento de mudanças ortográficos e morfossintáticas observadas na leitura de textos de sincronias pretéritas. Por outro lado, embora ilustrem a variação diacrônica com uma cantiga medieval, como se vê na transcrição acima, não se verifica uma abordagem interdisciplinar desse tipo de variação. Mesmo no capítulo sobre o Trovadorismo, tradicionalmente reconhecido como o primeiro momento literário de língua portuguesa, não há considerações de natureza histórico-linguística a respeito do galego-português, variedade das obras trovadorescas.

Campos e Assumpção (2016) destacam-se em relação às demais coleções analisadas por fornecerem um tratamento teórico da variação diacrônica. O volume avaliado da coleção "Esferas das linguagens" dedica três capítulos à variação linguística, intitulados "Variedade linguística brasileira", "Variações Linguísticas" e "A língua portuguesa no mundo". No primeiro, as autoras abordam a constituição sócio-histórica do português brasileiro, destacando a contribuição de outras línguas para a sua formação; reconhecem, ainda, influências mais recentes, do ponto de vista lexical, resultantes das imigrações de europeus ocorridas no País no início do século XX:

\footnotetext{
Diálogo entre as línguas faladas no Brasil

Na língua portuguesa falada no Brasil, desde a chegada dos portugueses até hoje, as mudanças foram muitas. Uma grande quantidade de termos que usamos foi importada de outras línguas e gradualmente se aportuguesou.

Contribuições de outras línguas

Para refletir sobre a língua que se fala atualmente no brasil, leia o artigo de Leandro Norloch.

As línguas do Brasil

Somos todos poliglotas

Árabe, iorubá, tupi, cantonês, catalão, provençal. A cada vez que você abre a boca para falar o bom e velho português brasileiro, acaba soltando palavras dessas línguas e de outras 30. Isso por baixo, já que ninguém sabe ao certo quantas línguas tiveram termos aportuguesados desde o ano 218 a.C., quando os romanos apareceram na Península Ibérica e começaram a formar o que seria a língua portuguesa.

"Todas as línguas e culturas do mundo vivem do contato e do diálogo", diz Caetano Galindo, professor de Filologia da Universidade Federal do Paraná. As palavras estrangeiras aportuguesadas são como fósseis: contam a história dos povos que conviveram com quem falava a "língua de Camões". Povos em florescimento artístico deixaram termos sobre espetáculos e cultura. É o caso do italiano. Povos guerreiros enriqueceram o nosso vocabulário sobre a guerra. "Canivete", "bando", "trégua" e a própria "guerra" vieram dos bárbaros germânicos (suevos e visigodos), que dominaram a Península Ibérica entre os séculos V e VII. (CAMPOS; ASSUMPÇÃO, 2016, p.47).
}

Campos e Assumpção (2016), na medida em que tratam da formação do português brasileiro, apresentam um tópico que pode ser considerado inovador no rol da variação linguística em livros didáticos. No entanto, como se pode verificar na transcrição acima, a ênfase na mudança linguística pela via lexical suscita críticas à abordagem das autoras: a variação, seja diacrônica, seja sincrônica, não deve ser reduzida a aspectos lexicais. 
No caso da formação do português brasileiro, caberia mostrar, com as devidas adequações didáticas, que, durante os primeiros séculos de colonização, o intenso contato entre o português e, principalmente, as línguas africanas promoveu também mudanças sintáticas importantes, sobretudo no paradigma da concordância verbo-nominal (cf. LUCCHESI, 2015).

No capítulo intitulado "A língua portuguesa no mundo", Campos e Assumpção (2016) apresentam, de maneira mais explícita, considerações teóricas sobre a variação diacrônica. Chama a atenção, nesse capítulo, a presença de uma subseção para definir a mudança linguística e, na sequência, a sua classificação com base nos níveis da língua: "mudanças sonoras e gramaticais" e "mudanças semânticas" (CAMPOS; ASSUMPÇÃO, 2016, p. 126-127).

Destaca-se também a presença de fragmentos de textos datados de diferentes séculos e representativos de gêneros textuais distintos: texto notarial, cantiga, novela de cavalaria, etc. Como se discute adiante, o contato com registros de sincronias pretéritas é imprescindível à compreensão da variação - diacrônica e sincrônica -, o que, considerando a formação de estudantes do Ensino Médio, constitui estratégia didática que se mostra eficaz para o combate ao preconceito linguístico.

Por fim, como se transcreve a seguir, as autoras sistematizam as ideias arroladas ao longo do capítulo, mencionando questões cruciais sobre a variação diacrônica, como a implementação da mudança linguística e a natureza diversa, do ponto de vista gramatical, dos fenômenos atinentes a esse tipo de variação:

\begin{abstract}
Sistematizando a prática linguística
Como acontecem as mudanças nas línguas?

Elas nem sempre são percebidas pelos falantes porque são lentas e graduais, só identificadas de tempos em tempos. Na língua usada pela coletividade, ocorrem variações num dado momento histórico. Aquelas que permanecem são incorporadas à língua escrita, entram para o dicionário, ganham status de língua padrão e marcam mudanças na evolução da língua.

Essas mudanças ocorrem de forma diferente e com ritmo próprio em cada comunidade. Determinados grupos sociais trocam os seus hábitos linguísticos, ao passo que outros preservam traços de estágios anteriores da língua. É o que acontece com muitas comunidades no interior do Nordeste e do Sudeste (São Paulo e Minas Gerais), menos expostas a influências linguísticas. Verifique a seguir alguns exemplos do linguajar brasileiro preservado por séculos. São um verdadeiro patrimônio linguístico.
\end{abstract}

$\begin{array}{lll}\text { abastar }=\text { bastar } & \text { dezanove }=\text { dezenove } & \text { manteúda }=\text { mantida } \\ \text { antão }=\text { então } & \text { dorminhar }=\text { dormir } & \text { pranta }=\text { planta } \\ \text { avoar }=\text { voar } & \text { entonces }=\text { então } & \text { sear }=\text { semear } \\ \text { basculhar = vasculhar } & \text { fruita }=\text { fruta } & \text { sobaco }=\text { sovaco } \\ \text { dereito }=\text { direito } & \text { lançol }=\text { lençol } & \text { teúda }=\text { tida } \\ \text { despois }=\text { depois } & \text { luita }=\text { luta } & \text { reição }=\text { traição }\end{array}$

Como vimos, as mudanças na língua portuguesa são lentas; nascem de variações da fala consolidadas após um tempo de uso. Podem ocorrer por adição, perda ou troca de fonemas (unidades de som); troca de lugar do fonema na palavra; alterações na sintaxe (combinações entre as palavras da frase); alterações semânticas: mudança de sentido, nascimento (neologismo) e morte de palavras. (CAMPOS; ASSUMPÇÃO, 2016, p. 129). 
Dessa forma, observa-se que a abordagem da variação diacrônica apresentada por Campos e Assumpção (2016) é bastante pertinente, sobretudo por representar, entre os materiais analisados, o que discute, com mais vagar, a mudança linguística. Falta, contudo, um conjunto de atividades que proporcione ao aluno a prática das questões teóricas exploradas: no decorrer de ambos os capítulos destinados à variação diacrônica, os exercícios não se caracterizam como propostas de análise linguística sob o viés histórico; baseiam-se, na realidade, em procedimentos de leitura e interpretação. Ademais, a obra carece de um diálogo com a Literatura, embora, por exemplo, as mudanças sonoras e gramaticais sejam ilustradas por meio de uma cantiga medieval.

O volume avaliado da coleção "Novas palavras" também apresenta um capítulo para tratar da variação linguística e, ao abordar os seus tipos, dedica uma subseção à variação histórica:

\begin{abstract}
A variação histórica
O trecho abaixo é o início de um importante documento da história do Brasil. Leia-o:

Snõr

posto que o capitam moor desta vossa frota e asy os outros capitaães screpuam a vossa alteza a noua do acha mento desta vossa terra noua que se ora neesta naue gaçom achou, nom leixarey tambem de dar disso minha comta a vossa alteza asy como eu milhor poder ajmda que pera o bem contar e falar o saiba pior que todos fazer [...]

CAMINHA. Pero Vaz. Carta a El Rei D. Manuel (ortografia original). 2010. Disponível em: $<$ https://pt.wikisource.org/wiki/Carta a El Rei D. Manuel (ortografia original)>. Acesso em: 19 jan. 2016.

E então, conseguiu ler?

Certamente você estranhou a ortografia de algumas palavras, mas, com algum esforço, talvez tenha conseguido perceber o sentido da maioria delas. Acontece que era assim mesmo que se escrevia em 1500, quando Pero Vaz de Caminha escreveu a sua carta ao rei de Portugal, relatando a chegada dos portugueses ao Brasil.

Agora leia uma "versão atualizada" do trecho acima:

Senhor

Posto que o capitão-mor desta frota, e assim os outros capitães escrevam a Vossa Alteza a nova do achamento desta vossa terra nova, que ora nesta navegação se achou, não deixarei também de dar nisso minha conta a Vossa Alteza, assim como eu melhor puder, ainda que - para o bem contar e falar - o saiba pior que todos fazer. Comparando os dois trechos anteriores, é fácil perceber que, de 1500 para cá, nosso idioma, como é natural, foi mudando ao longo do tempo.
\end{abstract}

(AMARAL et al., 2016, p. 161)

Embora esclareçam, em outra parte da subseção transcrita, que "...as formas de falar se alteram; mudam-se as palavras, a grafia, as formas de estruturar as frases e, muitas vezes, os significados das palavras" (AMARAL et al., 2016, p. 162), pode-se notar que os autores apresentam a variação diacrônica com ênfase em aspectos ortográficos, o que pode gerar a inferência inadequada de que a mudança linguística acontece da escrita para a fala ou mesmo se restringe à escrita ${ }^{7}$.

A questão do texto como veículo para o estudo da mudança linguística é bastante discutida na Linguística Histórica (cf. MATTOS E SILVA, 2008). Trata-se, portanto, de um aspecto teórico-metodológico para o qual professores e elaboradores de materiais didáticos devem estar atentos, uma vez que, para entrever estágios anteriores de uma língua a partir de textos escritos, deve-se considerar que, para além de problemas de conservação ou de edição, esses registros não refletem fielmente o sistema linguístico nos seus usos reais.

\footnotetext{
${ }^{7}$ Nesse sentido, cabe aqui a lembrança de que, em 2009, quando entrou em vigor o Novo Acordo Ortográfico da Língua Portuguesa, a grande mídia brasileira, refletindo o senso comum, noticiava "mudanças na língua" por meio de afirmações e reportagens que, não distinguindo adequadamente ortografia e demais níveis da língua, apontavam a escrita como a própria língua.
} 
Não há, em Amaral et al. (2016), considerações interdisciplinares entre a variação diacrônica e tópicos da (história da) Literatura. Verifica-se, então, mais um caso em que os autores ilustram a mudança linguística por meio de textos tradicionalmente trabalhados nas aulas de Literatura, mas não estabelecem, por exemplo, relações entre a história da língua e a história da Literatura. Nessa obra, não se identificam também atividades que possam ser descritas como propostas de análise linguística em perspectiva diacrônica. Na transcrição a seguir, nota-se que a perspectiva de análise subjacente à atividade pode ser considerada mais estilística que diacrônica:

5. O escritor Carlos Drummond de Andrade produziu uma crônica na qual usou, propositalmente, uma linguagem desatualizada, com muitos arcaísmos, isto é, palavras e expressões "ultrapassadas". Leia o trecho dessa crônica:

\section{Antigamente}

Antigamente, as moças chamavam-se "mademoiselles" e eram todas mimosas e muito prendadas. Não faziam anos: completavam primaveras, em geral dezoito. Os janotas, mesmo não sendo rapagões, faziam-lhes pé-de-alferes, arrastando a asa, mas ficavam longos meses debaixo do balaio. E se levavam tábua, o remédio era tirar o cavalo da chuva e ir pregar em outra freguesia [...]

As pessoas, quando corriam, antigamente, era para tirar o pai da forca, e não caíam de cavalo magro. Algumas jogavam verde para colher maduro, e sabiam com quantos paus se faz uma canoa. O que não impedia que, nesse entremente, esse ou aquele embarcasse em canoa furada. Encontravam alguém que lhes passava a manta e azulava, dando às de Vila-Diogo.

Os mais idosos, depois da janta, faziam o quilo, saindo para tomar a fresca; e também tomavam cautela de não apanhar o sereno. Os mais jovens, esses iam ao animatógrafo, chupando balas de alteia. Ou sonhavam em andar de aeroplano. Estes, de pouco siso, se metiam em camisa de onze varas e até em calças pardas; não admira que dessem com os burros n'água.

Embora sem saber da missa a metade, os presunçosos queriam ensinar padre-nosso ao vigário, e com isso punham a mão em cumbuca. Era natural que com eles se perdesse a tramontana. A pessoa cheia de melindres ficava sentida com a desfeita que Ihe faziam quando, por exemplo, insinuavam que seu filho era artioso. É verdade que às vezes os meninos eram encapetados, e chegavam a pitar escondido atrás da igreja. As meninas não: verdadeiros cromos, umas teteias.

[...]

Mas tudo isso era antigamente, isto é, outrora.

ANDRADE, Carlos Drummond de. Poesia e Prosa. Rio de Janeiro: Nova Aguilar, 1988. p. $1709-1710$.

É bem possível que você tenha compreendido o significado de algumas expressões e seja capaz de "traduzi-las" para a linguagem atual; há outras, no entanto, que talvez você só consiga "modernizar", atualizar, com a ajuda de pessoas mais velhas. Levando isso em conta, responda aos itens de a a d.

a) Atualize as expressões a seguir. Use palavras e frases de sua linguagem cotidiana, até mesmo gírias.

1. faziam-lhe pé-de-alferes

2. arrastando a asa

3. ficavam longos meses debaixo do balaio

4. levavam tábua

5. ensinar padre-nosso ao vigário

6. as meninas eram umas teteias

b) Há, no texto, alguma expressão que você e as outras pessoas de sua faixa de idade utilizam para se comunicar? Se houver, transcreva-a(s).

c) Transcreva uma expressão que, pela estranheza, você julga ser a mais antiga do texto.

d) Suponha que um amigo seu tenha uma namorada e, conversando com você, diga que ela é "mimosa e prendada". Como você agiria em relação a essa forma de falar empregada por ele?

(AMARAL et al., 2016, p.172). 
Além de não atenderem ao critério da abordagem interdisciplinar da variação diacrônica, os livros analisados têm em comum a completa ausência de propostas de projetos pedagógicos ${ }^{8}$ baseadas nesse tipo de variação.

As análises aqui empreendidas - que não visam, vale reafirmar, a questionar a qualidade didático-pedagógica das coleções consultadas - assinalam a necessidade de haver mais atenção à variação diacrônica na aula de Português. Enquanto os livros didáticos não se aprimoram nesse quesito, a fim de fornecer um suporte teórico e prático para professoras e professores que, em sua imensa maioria, não dispõem de formação adequada ou suficiente para o trabalho com a mudança linguística, algumas sugestões, ainda que genéricas, são válidas para garantir algum espaço à variação histórica na sala de aula. Assim, como resposta a uma das questões norteadoras do presente trabalho - Como o professor pode trabalhar com a variação diacrônica? -, apresentam-se, na seção a seguir, sugestões didáticas pautadas pela abordagem da mudança linguística no Ensino Médio.

\section{A variação diacrônica na aula de Português}

Nas aulas dedicadas à variação linguística, é esperado que a professora assuma o objetivo principal de atestar o caráter variável e mutável da língua. Tendo realizado um trabalho bem-sucedido, muito provavelmente, sua turma estará mais convencida da natureza variável da língua do que da mutável. A ausência de considerações diacrônicas, no trabalho com a variação, em sala de aula, dificulta, portanto, a compreensão da mudança linguística, aspecto também imprescindível para desconstruir a alegada homogeneidade linguística que persiste no imaginário linguístico-social.

Tão necessário quanto mostrar as diferenças linguísticas diatópicas e estilísticas, por exemplo, é atestar a variação no tempo, expondo o aluno a textos de sincronias pretéritas. Dessa maneira, o objetivo da aula de Português sobre variação - ou sobre quaisquer tópicos para os quais seja possível lançar um olhar variável - deve ser ampliado, no sentido de contemplar a variação sob a perspectiva histórica.

Assim, uma primeira sugestão para atingir adequadamente esse objetivo é desenvolver, em sala de aula, atividades que envolvem leitura e análise de textos representativos de sincronias pretéritas. Ainda que, deve-se destacar, os registros escritos representem apenas uma "aproximação" da sincronia que se quer investigar (MATTOS E SILVA, 2008, p. 24), somente por meio deles é possível (entre)ver a língua de períodos mais remotos. Pode-se, então, entre outras estratégias, promover o contato do aluno com esses registros a partir de uma sequência didática que integre o estudo da história da língua portuguesa ao estudo da literatura trovadoresca.

Essa sequência pode iniciar-se pela discussão sobre as origens do português, apresentando-se os estágios conhecidos da sua evolução, representados, genericamente, pelo seguinte continuum: indoeuropeu > latim (vulgar) > romance do noroeste da Península Ibérica > galego-português > português (lusitano) > português brasileiro ${ }^{9}$. Após as considerações geopolíticas necessárias à compreensão do

\footnotetext{
${ }^{8}$ Vale assinalar que, no Guia do PNLD, "também se observa a presença de projetos que constroem contextos mais significativos para a formação de leitores e escritores" (BRASIL, 2018, p. 16).

${ }^{9}$ Esse continuum está sujeito a diversos questionamentos e/ou refinamentos. Entretanto, em termos didáticos, pode ser considerado suficientemente adequado para um trabalho em que o público-alvo sejam estudantes do Ensino Médio.
} 
continuum, a discussão deve focar a sincronia codificada pelo galego-português, por ser definida como a fase arcaica da língua portuguesa (aproximadamente do século XII à segunda metade do século XIV).

Assim, nas origens da língua portuguesa, encontra-se também a gênese da sua Literatura: o estudo da produção literária medieval - escrita em galego-português e tradicionalmente denominada Trovadorismo ${ }^{10}$ - pode assumir um caráter híbrido, envolvendo a análise de aspectos históricos, estilísticos e linguísticos.

Na segunda etapa de execução da sequência didática, é possível iniciar o trabalho com os textos trovadorescos por meio de atividades que promovam: i) o reconhecimento de características estilísticas e temáticas para justificar a sua classificação literária (cantiga de amigo, cantiga de maldizer, novela de cavalaria etc.); ii) a descrição de aspectos lexicais e gramaticais que evidenciam o caráter arcaico dos textos em análise e iii) a comparação com textos atuais tanto pela perspectiva literária quanto pela perspectiva linguística, para a identificação de permanências e/ou alterações temáticas/estilísticas/lexicais/gramaticais.

A mesma sugestão pode ser aplicada para o estudo de outros movimentos literários, como, por exemplo, o Quinhentismo. Nesse caso, a análise do contexto histórico do movimento, marcado pelas expedições colonizadoras dos portugueses, permite que se abordem dois processos relativos à sóciohistória da língua portuguesa, a saber, a ampliação dos espaços lusófonos no mundo e a formação do português brasileiro.

Outro tipo de atividade, que pode ser executado a partir de um texto trovadoresco ou quinhentista, diz respeito à seleção de formas linguísticas arcaicas que, permanecendo nas variedades populares do português, são hoje estigmatizadas. Como se observa nos fragmentos abaixo, retirados de uma hagiografia do século XIV (MACHADO FILHO, 2009), as formas em destaque são ainda detectadas em algumas variedades do português brasileiro:

(1) E todos choravam e el soo era ledo, ca sem dulta sabia que ya dereytamente aa celestial gloria. E preguntarom-lhi se temia a morte.

(2) E pois que hi fez sa romaria e se quis tornar pera onde veera, os marinheyros que hi andavam disserom que eram cansados e que nõ podiam remar.

Como essas formas são marcas salientes para identificação de um grupo de falantes historicamente excluído, recai sobre elas o preconceito linguístico. Dessa forma, a professora deve discutir, a partir desses dados empíricos, a fluidez e convencionalidade da normatização linguística. Comprova-se, assim, por um viés científico, que a noção de "erro" na língua resulta de uma avaliação social, já que o "desvio", nesse caso, é, na realidade, uma permanência linguística.

Pode-se, ainda, através do trabalho com textos de diferentes sincronias, abordar questões ortográficas e gramaticais (sintáticas, morfológicas, semânticas etc.). É possível, por exemplo, mostrar oscilações ortográficas, inclusive em um mesmo texto, como reflexo de fenômenos de mudança ou da

\footnotetext{
${ }^{10}$ Existem muitas críticas ao ensino de Literatura pautado pela periodização que resultou na definição de "escolas literárias". As sugestões apresentadas não devem, portanto, atrelar-se aos períodos literários, mas levar em consideração, na análise de textos (literários) antigos, aspectos relativos à construção do texto/discurso literário e aspectos histórico-linguísticos.
} 
ausência de uma norma, e a recorrência a abreviações, que não são, portanto, uma inovação provocada pelo advento da internet, conforme se vê, por exemplo, no seguinte trecho da "Crónica del-rei D. António", datada do século XVI:

(3) hũ escudejro natural da sidade deuora estamdo catjuo e pera morrer lhe mamdou djzer $\mathbf{q} \mathbf{p}$ amor de ds o qujzese Resgatar, pq Ihe paresja q se morrese catjuo q se não saluarja.

A análise de aspectos gramaticais, em perspectiva diacrônica, pode ser exemplificada pela identificação de mudanças morfossintáticas e semânticas. Assim, em (1), a forma "ca", hoje extinta, é uma conjunção explicativa equivalente a "pois". Embora fosse bastante frequente até o século XV, 0 desaparecimento dessa conjunção não gerou uma "lacuna" no sistema linguístico: a conjunção "pois", que, até o século XIV, também tinha sentido temporal (Em (2) acima, a forma "pois que" corresponde a "depois que"), passou a ser utilizada nos contextos antes ocupados por "ca", firmando-se como uma conjunção explicativa.

Uma análise dessa natureza é bastante ilustrativa para conduzir os estudantes à compreensão de que a mudança linguística não é um processo danoso à língua, mas inerente à sua evolução. Assim, a abordagem da variação diacrônica, em termos pedagógicos, é tão relevante quanto a da variação observada no português contemporâneo, uma vez que possibilita a compreensão do "fazer e refazer-se da língua, que atinge lenta e gradualmente forma, significado e uso das construções linguísticas" (LONGHINTOMAZI, 2014, p. 165).

Por fim, como proposta de projeto, o processo de formação da língua portuguesa pode tematizar um conjunto de atividades, envolvendo as disciplinas História, Geografia e Espanhol. Desse modo, os estudantes, em equipe, são orientados a pesquisarem sobre diferentes subtemas relacionados à história do português, como o processo de romanização, a divisão geopolítica, na Idade Média e Moderna, da Península Ibérica e a identificação dos traços linguísticos que aproximam a língua portuguesa do galego e do espanhol, o que deve ser feito sob a supervisão de professoras e professores das diferentes áreas a que esses subtemas se relacionam. Os resultados da pesquisa podem ser divulgados à comunidade escolar através de variados gêneros textuais, como memes, infográficos e poemas.

\section{Considerações finais}

Conforme atestam a Sociolinguística e demais teorias linguísticas baseadas na língua em uso, variação e mudança são fenômenos inerentes a todas as línguas naturais. Embora nem toda variação resulte em uma mudança, para uma compreensão adequada do funcionamento das línguas, não se deve hierarquizar o papel desses fenômenos.

Assim, a inserção da variação diacrônica no ensino de Língua Portuguesa deve ser efetivada: a análise da mudança linguística, em sala de aula, ao passo que promove a tomada de consciência sobre a natureza mutável da língua, estimula reflexões acerca da normatização/norma-padrão, contribuindo para o combate ao preconceito linguístico. 
Como a grande maioria das professoras e dos professores de Português não está apta a lidar com dados e fenômenos diacrônicos, é imprescindível que os livros didáticos representem um facilitador para o trabalho com a variação diacrônica, abordando-a de maneira didática e interdisciplinar.

\section{Referências}

AMARAL, E. et al. Novas palavras. 3a ed. São Paulo: FTD, 2016. Vol. 1.

AMORIM, F. S. Ensino do português brasileiro: por uma pedagogia descolonial. Web-Revista SOCIODIALETO, v. 05, p. 111-138, 2014.

ARAÚJO, A. A.; PEREIRA, M. L. S. Variação linguística em livro didático do ensino fundamental: propostas e tratamento. Letrônica, v. 10, p. 350-360, 2017.

BRASIL, Ministério da Educação e do Desenvolvimento; Secretaria de Educação Fundamental. Parâmetros Curriculares Nacionais: Língua Portuguesa. Brasília-DF: MEC/SEF, 1998.

- Secretaria de Educação Fundamental. Programa Nacional do Livro Didático de Língua Portuguesa. Brasília-DF: MEC/SEF, 2018.

CAMPOS, M. I. B.; ASSUMPÇÃO, N. Esferas das linguagens. São Paulo: FTD, 2016. Vol. 1.

CEREJA, W. R.; VIANNA, C. A. D.; DAMIEN, C. C. Português contemporâneo: diálogo, reflexão e uso. São Paulo: Saraiva, 2016. Vol 1.

COAN, M.; FREITAG, R. M. K. Sociolinguística variacionista: pressupostos teórico-metodológicos e propostas de ensino. Domínios de Lingu@Gem, v. 4, p. 173-194, 2010.

DUARTE, M. E. L. Sobre o ensino de gramática nos níveis fundamental e médio: por que como e quando? Matraga (Rio de Janeiro), v. 19, p. 41-60, 2013.

FARACO, C. E.; MOURA, F. M.; MARUXO Jr, J. H. Língua portuguesa: linguagem e interação. 3a ed. São Paulo: Ática: 2016. Vol. 1.

GÖRSKI, E. M.; COELHO, I. L.. Variação linguística e ensino de gramática. Working Papers em Linguística, v. 10, p. 73-91, 2009.

LIMA, R. J. Variação linguística e os livros didáticos de português. In: MARTINS, A. M.; VIEIRA, S. R.; TAVARES, M. A (Org.). Ensino de português e sociolinguística. São Paulo: Contexto, 2014, p. 115-132.

LONGHIN-TOMAZI, S. R. Mudança gramatical no sistema conjuncional: considerações para o ensino. In: MARTINS, M. A.; TAVARES, M. A. (Org.). Contribuições da sociolinguística e da linguística histórica para o ensino de língua portuguesa. Natal: EDUFRN, 2013, v. 1, p. 165-188.

LUCCHESI, D. Língua e SociedTade Partidas. a polarização sociolinguística do Brasil. São Paulo: Contexto, 2015.

MACHADO FILHO, A. V. L.. Um flos sanctorum trecentista em português. Brasília: Editora Universidade de Brasília, 2009.

MARINE, T. C.; BARBOSA, J. B. Em busca de um ensino sociolinguístico de Língua Portuguesa no Brasil. Signum: estudos de linguagem, v. 19, p. 185-215, 2016.

MARTINS, M. A.; TAVARES, M. A. (Org.). Contribuições da sociolinguística e da linguística histórica para o ensino de língua portuguesa. Natal: EDUFRN, 2013.

MARTINS, A. M.; VIEIRA, S. R.; TAVARES, M. A (Org.). Ensino de português e sociolinguística. São Paulo: Contexto, 2014.

MATTOS E SILVA; R. V. O Português Arcaico: Uma Aproximação. Vol. I. Lisboa: Imprensa Nacional - Casa da Moeda, 2008.

ZILLES, A. M. S.; FARACO, C. A. (Org.). Pedagogia da variação linguística: língua, diversidade e ensino. São Paulo: Parábola Editorial, 2015. 